\title{
Sacral Dimple
}

National Cancer Institute

\section{Source}

National Cancer Institute. Sacral Dimple. NCI Thesaurus. Code C87118.

A small hollow area or sinus present at birth and located just above the crease of the buttocks. In most cases, pilonidal dimples are benign and may just be accompanied by increased hair growth in the area. 